\title{
Comparison of 4th and 5th generation district heating systems
}

\author{
Dr. Oddgeir Gudmundsson ${ }^{1 *}$, Anders Dyrelund ${ }^{2}$ and Jan Eric Thorsen ${ }^{1}$ \\ ${ }^{1}$ Danfoss A/S, Climate Solution, Application \& Technology, 6430 Nordborg, Denmark \\ ${ }^{2}$ Ramboll A/S, Copenhagen, Denmark
}

\begin{abstract}
In a pursuit to increase the efficiency of district heating system there has been a continuous focus to reduce the system operating temperatures. This has led to the current state of the art district heating systems, commonly referred to as the 4th generation district heating, also known as low temperature district heating (LTDH). The success of the LTDH has fuelled a lot of research interest in district energy systems, one of the new research topics has been focusing on reducing the operating temperatures down to the ambient temperature (ATDH), commonly referred as $5^{\text {th }}$ generation district heating. In these systems the supply temperature is insufficient for fulfilling the heating demands of the connected buildings, which then requires end-user located heat pumps to raise the supply temperature to the level required by the buildings. As of today, number of ATDH systems have been realized as part of various research projects. The question however remains if ATDH brings additional benefits compared to LTDH. This paper compares the levelized cost of heat from these two systems types for two countries with different climate zones. The results of the analysis indicate that LTDH is the favourable solution in both countries.
\end{abstract}

\section{Introduction}

District heating is an evolving technology that has gone through couple of major development cycles, which have been classified as generations of district heating. The current state of the art generation is the $4^{\text {th }}$ generation district heating, also known as Low Temperature District Heating (LTDH) [1]. The generally increased focus on energy efficiency and green energy over the last decades has drawn a lot of attention and research interest to the district heating sector, which has embraced the attention and been active in experimenting with more innovations and concepts. One of the new concepts being considered is to operate with a supply temperature close to the ambient temperature, which opens for the possibility to utilize uninsulated pipe networks. As the supply temperature is insufficient for fulfilling either space heating or Domestic Hot Water (DHW) demands end-user located heat pumps are used to raise the supply temperature to the required level. These systems are commonly called the $5^{\text {th }}$ generation district heating [2] or Ambient Temperature District Heating (ATDH). In principle ATDH is neither a traditional district heating system nor a district cooling system, as it cannot deliver any service to the buildings without the help of an end-user heat pumps.

Both LTDH and ATDH can be considered as a response from the sector to the general trend of building energy renovations, which are significantly reducing the space heating demand. The building energy renovation trend is further enabling existing buildings, with radiators installations, to operate with supply temperature below $60^{\circ} \mathrm{C}$ for vast majority of the year [3], [4]. Another trend is the greater application of floor heating system for fulfilling the space heating demand, which have a maximum supply temperature demand of $45^{\circ} \mathrm{C}$, which has resulted in that the temperature requirements for DHW preparation determines the minimum supply temperature to the buildings. These trends have led to active research in Ultra-Low Temperature District heating (ULTDH), where the district heating system is designed with supply temperature of $40^{\circ} \mathrm{C}-45^{\circ} \mathrm{C}$, which is sufficient for fulfilling the building space heating demand, but requires a temperature boost for DHW preparation [5], [6], [7], [8]. The common results of the research into ULTDH is that it generally does not give economic benefits compared to LTDH.

With the increased focus on decarbonized energy systems the sector has further been looking into how it can take advantage of synergies it has with other energy sectors, in particularly the future renewable power sector. This has led to active research in the role of heat pumps in the future energy system, in particular how the heating sector can support the power sector in handling excess renewable power generation from intermittent renewable energy sources, like wind and solar [9], [10]. With heat pumps identified as one of the key technologies to decarbonize the heating sector the questions has been raised on the optimal location of the heat pump, the two extremes would be individual heat pumps at each end-user and a collective heat pump supplying multiple buildings via district heating network [11].

\footnotetext{
* Corresponding author: og@danfoss.com
} 
If looking specifically on a district heating system heat pumps can be connecting to the system at different locations. This gives room for two different viewpoints on the relationship between district heating and heat pumps:

1) The role of the heat pump is to provide service to the district heating system, such as a heat supply unit or a temperature booster unit.

2) The role of the district heating system is to be either a thermal source or sink for end-user located heat pumps.

Viewpoint 1 is the general viewpoint in LTDH systems, while viewpoint 2 is the general viewpoint in ATDH systems.

By taking a wider perspective on these two viewpoints the differences between these two system solutions can be considered in respect to system flexibility, resilience to disruptions and ability to include local heat sources. See [12] for an overview of robust, reliable and resilient systems and [13] for an overview of what makes district heating resilient.

While system flexibility can mean different things the most important for the future energy system is the flexibility to utilize intermittent energy sources and provide load services to other parts of the energy system, in particular to the power sector. In this respect the flexibility is directly related to the ability of the system to decouple the heat demand and the heat generation. While the ATDH is limited to the thermal flexibility of the building, which is generally in the range of hours to half a day, the LTDH can enable long term flexibility, measured in days to months, through a large centralized thermal storage. The key to the LTDH flexibility is that it operates at temperature levels that are directly useful for fulfilling the heating demands of the end-users.

While both systems types are based on mature, robust, and reliable technologies the key difference to resilience of those two systems is their ability to cope and recover from disruptions. An example of a critical disruption in respect to electrified heating systems, as considered in this analysis, would be power grid failures, see [14] for an overview of common power grid threats, average duration of outages due to various types of grid failures and a list of recent and significant grid failures in Europe. A power grid collapse would cause significant complications to both systems, due to the reliance on operation of either a central or end-user located heat pumps. In this respect the LTDH system would however have an advantage as centralized emergency boilers and electricity generator could provide basic heat supply to all connected buildings, while in the ATDH system each end-user would need to acquire and connect his own emergency boiler.

When it comes to utilization of local heat sources both systems have their specific advantages. If a local heat source is at low temperature level and the capacity is small the ATDH, which operates with low system temperatures, has the advantage that the owner of the heat source would not need to invest in an expensive heat pump to boost the temperature before supplying to the grid, as the temperature boost will be performed by the end-user heat pumps. If the heat source on the other hand is either large or at high temperature the LTDH would have the advantage. If the heat source is large the economy of scale of a large central heat pump would be more economical compared to having small heat pumps at each end-user. If the heat source has a high temperature it can be supplied directly into the LTDH system, while in case of ATDH either large exergy loss or high heat losses would need to be accepted.

As both LTDH and ATDH are relatively new concepts, LTDH dating back little over a decade and ATDH only couple of years, the focus has mainly been on demonstration of their applicability and gain experience and insights into their operation. What has been lacking is to compare the cost-effectiveness of these two heat supply options on equal terms, which is the focus of this analysis.

\section{Methodology}

The analysis considers a green field outer city area, consisting mainly of row-houses, villas and handful of small multi-apartment buildings. All calculations are performed using Matlab. Those include sizing the distribution networks, estimate the heating demands, estimating central and end-user heat pumps Coefficient Of Performance's (COP).

\subsection{System boundaries}

The boundaries of the analysis are from the exterior premises of the heat source to the secondary side of the building heat interface unit.

The following elements are within the system boundary:

- Central heat plant.

- Distribution network.

- End user heat interface unit. The following elements are outside the system boundary, as they are assumed identical to both supply systems or particularly location specific:

- Heat source for the central heat plant.

- Building heating installation.

Figure 1 visualizes the system boundaries of the study.

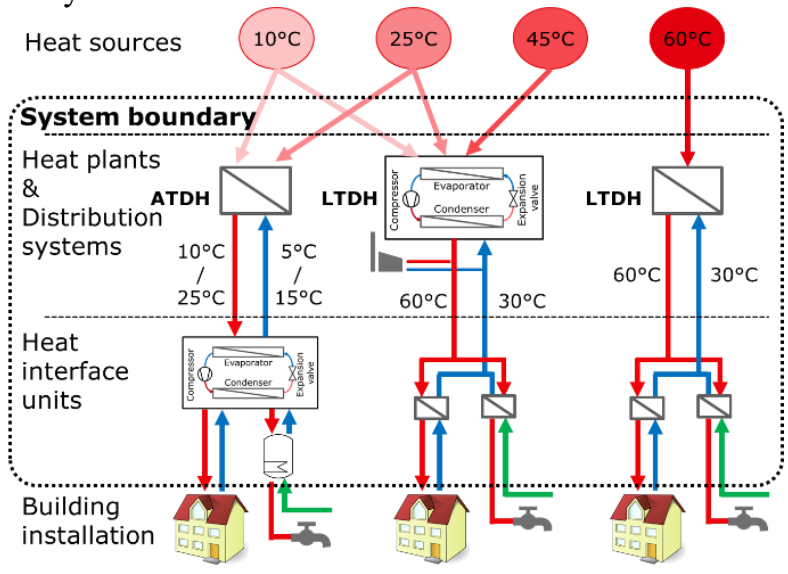

Figure 1. Visualization of the considered systems and the system boundary (dotted box). 


\subsection{Distribution network}

This analysis considers two heat supply solutions: 1) A LTDH system: A central heat pump maintains a supply temperature of $60^{\circ} \mathrm{C}$ and supplies sufficient heat to fulfil all end-user heating demands.

2) An ATDH system: A heat exchanger station maintains a supply temperature that is approximately the temperature level of the heat source. End-user located heat pumps raise the temperature to the requirements of space heating and DHW demands.

The system layout is modelled after a typical outer city area in the United Kingdom, see Figure 2.

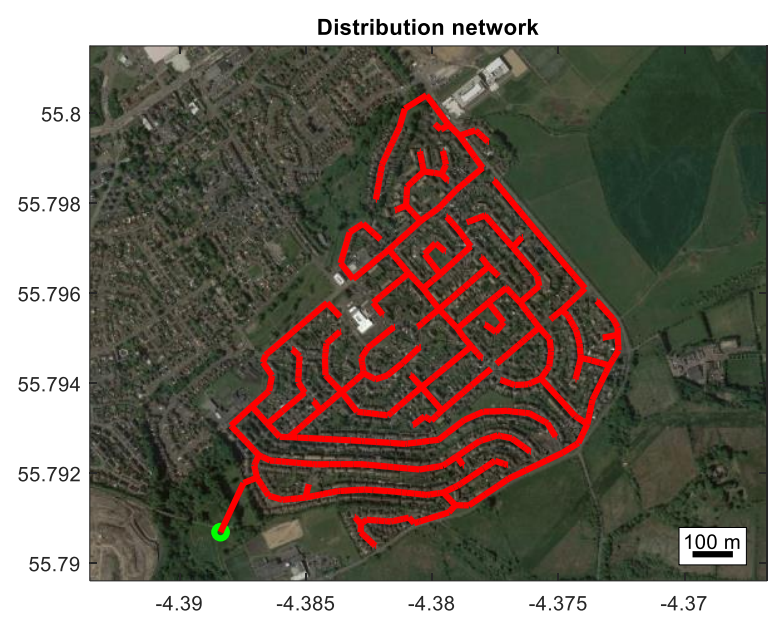

Figure 2. An overview of the distribution network layout.

The distribution system connects 1.693 residential units. The sizes of the residential units are randomly generated and have the size distribution as shown in Figure 3.

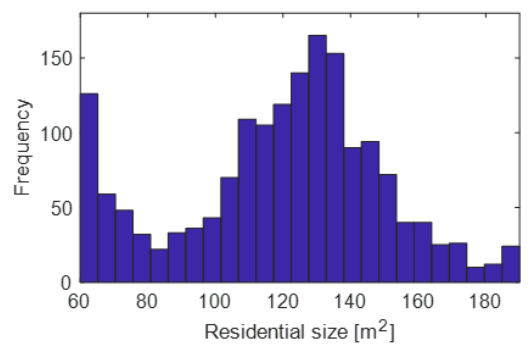

Figure 3. The size distribution of the residential units connected to the distribution network.

The supply system capacity demands take into account simultaneities of both space heating and DHW demands. For the ATDH system the power consumption of end-user heat pumps is excluded from the heating delivered by the ATDH system, e.g. it is assumed that the consumed power is used for heating of the building.

The simultaneity of space heating demands is based on standard procedures in Denmark, Eq. 1. The simultaneity of the DHW is based on Euroheat \& Power recommendations [15].

$$
S_{S H}=0,62+\frac{0,38}{n}
$$

Where $S_{S H}$ is the simultaneity factor and $n$ is the number of downstream connections.
The pipe network is dimensioned for each heat supply system using industry standards for flow velocities, $\max 2 \mathrm{~m} / \mathrm{s}$, and pressure drop per pipe meter, $\max 150 \mathrm{~Pa} / \mathrm{m}$. For the LTDH system insulation standard series 2, according to the EN253 standard, is applied. The analysis applies the preferred pipe system for each country, twin pipes for Denmark and a set of single pipes for the United Kingdom. For the ATDH system uninsulated pipes are applied.

\subsection{Heat sources}

The reason for not including the heat source within the system boundary is to decouple the analysis from specific types of heat sources, which could be sea, lake, river, sewage, mine water, low temperature geothermal or waste heat from industry processes. With the chosen boundary condition, the potentially complex heat source is reduced to simple temperatures. To make the analysis valid over a range of heat sources, temperatures of $10^{\circ} \mathrm{C}$, $25^{\circ} \mathrm{C}, 45^{\circ} \mathrm{C}$ and $60^{\circ} \mathrm{C}$ are considered.

In the analysis the LTDH systems are designed to deliver at minimum $90 \%$ of the heating demand through a centralized heat pump, which utilizes the same heat source as the ATDH network. The remaining heat demand, which occurs at the coldest period of the year, is delivered by a gas peak load boiler. This is a common approach and equivalent to a household heat pump relying on electric resistance heating during the peak heating demand. This is a standard practice to reduce the costly peak power generation capacity, which is only utilized for few hours per year.

As the COP of a heat pump is dependent on the temperature level of both the heat source and the heat sink it important to estimate the COP for each system variant. For the LTDH variants the central heat pump $\mathrm{COP}$ is estimated based on the heat source temperature and the design operating temperature of the district heating system. For the ATDH variants the end-user heat pump COP is estimated based on the heat source temperature and an ideal floor heating operating temperature curve for a given outdoor temperature, see Figure 4. In practice floor heating installations are although operated with an on/off principle outside the design condition, which would lead to pulses with higher supply temperatures than shown in Figure 4, which would lead to slightly lower annual COP of the end-user heat pumps than considered in this analysis.

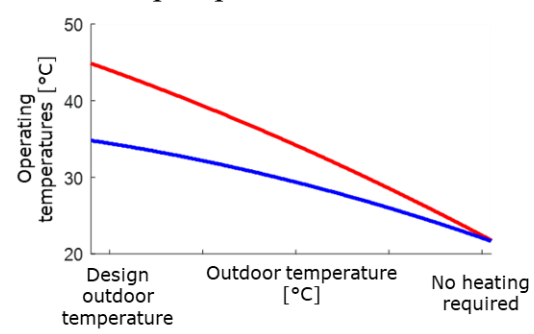

Figure 4. Principle diagram for estimating the ideal supply and return temperature for floor heating installations. 


\subsection{Building energy class, heating installation and heat demands}

To address wide range of conditions the analyses considers two building energy classes, a high and low energy classes, with peak heating demand of $50 \mathrm{~W} / \mathrm{m}^{2}$ and $25 \mathrm{~W} / \mathrm{m}^{2}$ respectively. For both energy classes the analysis assumes floor heating installations for delivering space heating demands.

The hourly space heating demand is estimated by using standard climate profiles for the considered areas, Copenhagen, Denmark, and London, the United Kingdom. Based on the standard climate profile of Copenhagen the space heating demands are 15 $\mathrm{MWh} /$ year and 7,5 MWh/year for the average high and low energy buildings respectively. For the standard climate profile of London the space heating demands are 11,4 MWh/year and 5,7 MWh/year for the average high and low energy buildings respectively.

The DHW demand is set at $2 \mathrm{MWh} /$ year per connection, which would normally be considered in the low end for DHW demands. In addition to the DHW demand heat losses of the DHW preparation units are added, $0.27 \mathrm{MWh} /$ year for LTDH instantaneous heat exchanger units and $0.70 \mathrm{MWh} /$ year for ATDH storage tank units. The daily DHW demand is distributed over the day based on the daily DHW profile given in [11], which has clear morning and evening peaks.

\section{Economics}

\subsection{Technology costs}

One of the key challenges when performing comparison studies of complex systems is to acquire quality data of performances, investments, and operational costs of technologies.

Based on the boundary conditions shown in Figure 1 the analysis considers the cost of installing, operating, and maintaining:

a) A central heat plant.

b) A distribution pipe network and service pipes.

c) A building heat interface unit, which in this analysis is either a district heating substation or end-user heat pump.

For a) the analysis relied on the Danish Energy Agency (DEA) Technology Catalogues [16]. In the case of the United Kingdom the economic parameters were adjusted from Danish condition to United Kingdom conditions using Purchasing Power Parities published by Eurostat ${ }^{1}$.

For b) the analysis relied on economic data from district heating project experience of Ramboll A/S in Denmark and Logstor $\mathrm{A} / \mathrm{S}$ in the United Kingdom for the LTDH case. Due to the general low number of realized ATDH systems there is currently no economic data available on the cost of establishing the ATDH

\footnotetext{
${ }^{1}$ https://ec.europa.eu/eurostat/statisticsexplained/index.php/Comparative price levels for in vestment
}

distribution network. In effort to estimate the cost of the ATDH distribution network the cost of the pipe network was related to the reduction of the required trench for a given pipe dimension compared to an equivalent dimension of an insulated single pipe trench. This approach gives on average $40 \%$ discount for installing an uninsulated pipe compared to an insulated pipe of equal diameter.

For c) the analysis relied on the Danish Energy Agency Technology Catalogue on individual heating plants [17] for Denmark and market experience of the Danfoss United Kingdom organization for the United Kingdom.

The following costs are not included in the analysis, as they are assumed equal to both the LTDH and the ATDH:

1) Development of the thermal source.

2) Utility administration cost.

a. The average administration cost in Danish utilities in 2015 was on average 65 EUR per connection.

3) The cost and operation of heat meters.

a. The average heat meter fees in Danish utilities was $65 \mathrm{EUR} / \mathrm{year}$ in 2020.

In this analysis all investments, individual as well as utility financed, are subjected to a discount rate of $3 \%$, which is approximately the social cost of capital [18].

\subsection{Energy prices}

When comparing collective and individual solutions it is important to consider that collective solutions using large amounts of fuels/electricity can benefit from wholesale prices. For transparency published Eurostat energy prices, excluding recoverable taxes and levies, for non-households consumer are used for the LTDH system [19].

The cost of the natural gas consumed by the LTDH peak load boiler is based on published Eurostat gas prices [20]. Using natural gas as a peak load fuel in the LTDH system will inevitably lead to higher $\mathrm{CO} 2$ emission compared to the ATDH system. To balance the 


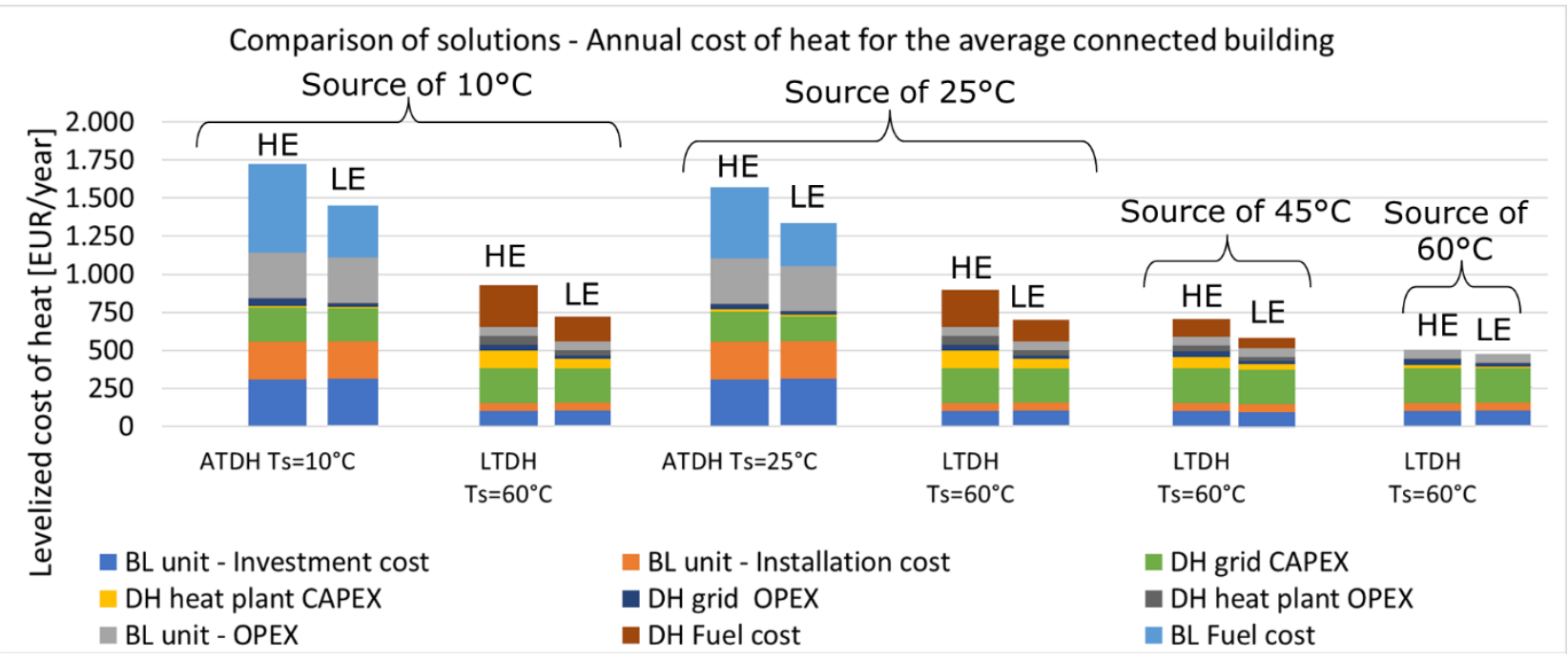

Figure 5. The annual levelized cost of heat for the average high energy (HE) and low energy (LE) consuming building (BL) in Copenhagen, Denmark, for ATDH and LTDH systems and thermal source temperatures. Ts represents system supply temperature.

additional $\mathrm{CO} 2$ emissions from the natural gas consumption green certificates could be applied. As of $21^{\text {st }}$ of August 2020 the EUA carbon emissions were trading at 25.62 EUR/ton ${ }^{1}$. Given IPCC emission factors for stationary combustion of natural gas [21] the additional cost of green certificates would results in additional cost of 6,9 EUR/year for high energy buildings and $4 \mathrm{EUR} /$ year for low energy buildings.

In case of the ATDH system the end-user has the responsibility for the cost of operating the heat pump. Although Eurostat publishes electricity prices for larger residential users, consumption above $5 \mathrm{MWh} /$ year, those prices do not give a correct image of the actual prices for electrified heating in neither Denmark nor the United Kingdom. To account for that the Eurostat published prices, which were 186.4 EUR/MWh and 192.4 EUR/MWh, excluding VAT, for Denmark and United Kingdom respectively in the second half of 2019 [22], were adjusted to more representative local conditions. In Denmark a subsidy of $25 \%$ is given to electricity used for heating, resulting in electricity price of $139.8 \mathrm{EUR} / \mathrm{MWh}$. While there is not a subsidy for electrified heating in the United Kingdom households can optimize their electric consumption based on the electricity tariff system, which commonly offers offpeak, normal and peak rates. In this analysis it is assumed that the end-user will optimize the operation of the heat pump according to the tariff system and achieve on an average $25 \%$ savings compared to the Eurostat price level, resulting in an average electricity price of 144.3 EUR/MWh.

\section{Results}

The results of the analysis are shown in Figure 5 for Copenhagen and Figure 6 for London. The figures show the annual levelized cost of heating for the average high and low energy buildings. When comparing the different cases shown in Figure 1 it is important to compare the results for each thermal source at a time. Cross

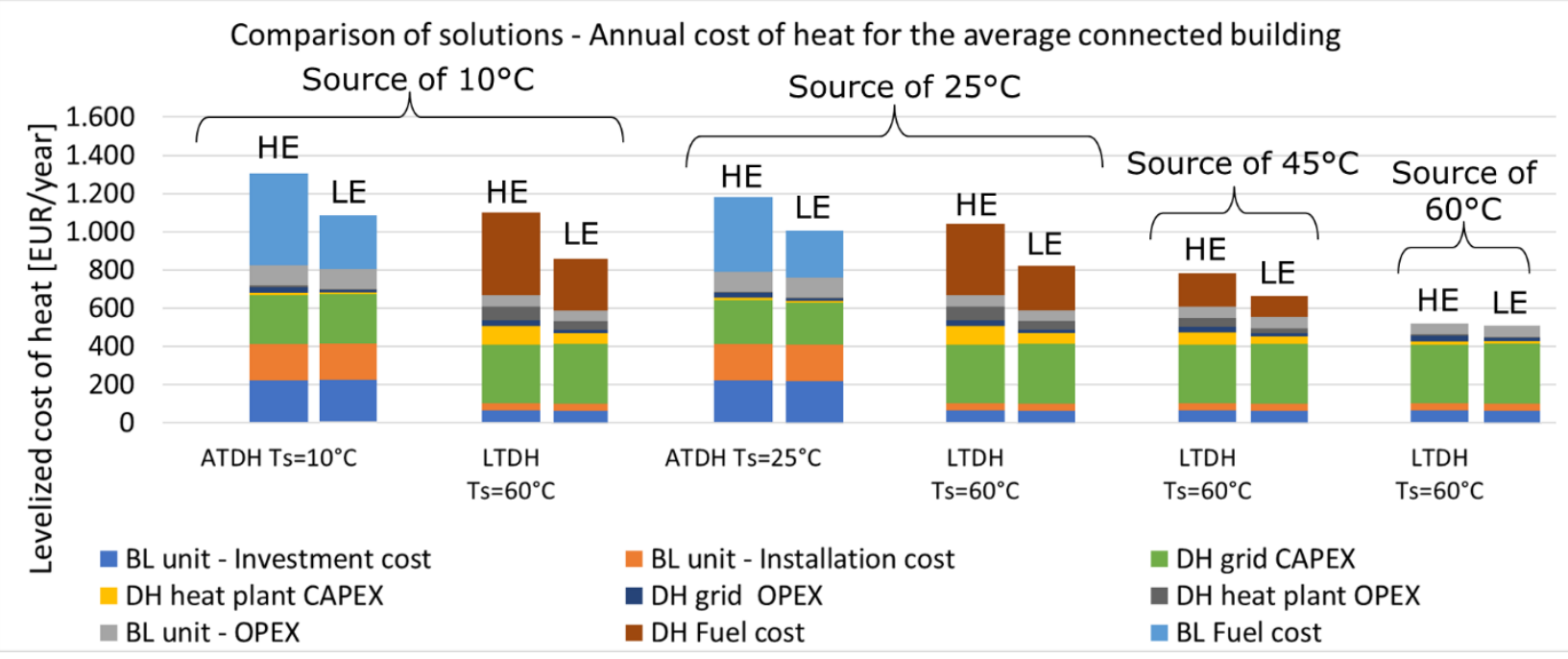

Figure 6. The annual levelized cost of heat for the average high energy (HE) and low energy (LE) consuming building (BL) in London, United Kingdom, for ATDH and LTDH systems and thermal source temperatures. Ts is represents system supply temperature.

\footnotetext{
${ }^{1} \underline{\text { https://carbon-pulse.com/category/eu-ets/ }}$
} 
comparing between thermal sources will lead to wrong conclusions, because if a high temperature heat source would be available it would naturally be used by both system types. Further, from above it should be clear that the analysis does not show a full picture of the heating cost and it can therefore not be used for comparing the considered supply systems to other heat generation technologies, for example individual natural gas boilers or heat pumps. The comparison between LTHD and individual heat supply units in Denmark is the topic of [11].

\subsection{Economic comparison}

Figure 5 and Figure 6 show that the levelized cost of heat follows the same trends in both Denmark and the United Kingdom, as would be expected. The differences are though much more decisive in Denmark compared to the United Kingdom. In Denmark the LTDH is 43\%$46 \%$ more cost efficient for high energy buildings and $48 \%-50 \%$ for low energy buildings. In the United Kingdom LTDH is $12 \%-16 \%$ more cost efficient for high energy buildings and 19\%-22\% for low energy buildings.

The reasons for the cost efficiency of LTDH is economy of scale of central heat pumps, access to less costly input energy and simpler building interface units. These factors more than compensate for the additional cost of the insulated pipe network and the associate distribution heat losses in LTDH systems compared to ATDH. This is independent on if the buildings are low or high energy buildings, since most of the heating cost becomes fixed cost as the heating demand becomes lower.

\subsection{Country comparison and considerations}

While the intention of the study is not to compare the cost of heating between the countries the results give way for reflecting on the differences between the countries. There are three aspects that can be specifically considered, the cost of the distribution network, the cost of the district heating fuel (electricity) and the cost of maintaining the end-user heat pumps.

For the distribution network the cost in the United Kingdom is significantly higher compared to Denmark. This has two reasons, first one is market matureness, were Denmark has a long history of district heating and extensive knowhow in establishing the system. As of today, the indicated project prices for establishing a distribution network in the United Kingdom are on average $15 \%$ higher compared to Denmark for same type of pipes. This indicates a cost saving potential as the market in the United Kingdom matures. Another difference is the preferred piping systems, single pipes in the United Kingdom and twin pipes in Denmark. The experience in Denmark shows that by applying twin pipes the cost of establishing the distribution network can be reduced by $15 \%$ compared to single pipes. Additional benefit is that heat loss during operation will be significantly reduced. If the same cost relationship in
Denmark holds in the United Kingdom there is a significant potential to reduce the cost of establishing the distribution network for LTDH systems.

The second main difference in the cost of the electricity to the utility. The ability of the district heating in Denmark to access low cost electricity gives LTDH a significant advantage compared to ATDH. In the United Kingdom the difference between the non-household and household electricity prices is much smaller. Since this is based on local tax and tariff systems it is unlikely that any improvements potential can be inferred between the two countries.

The third is the estimated cost of operating and maintaining (OPEX) end-user heat pumps. The estimated OPEX is significantly lower in the United Kingdom compared to Denmark. The authors do not see any clear reason why that is the case. Most likely either the Danish Energy Agency is overestimating the OPEX of end-user heat pumps or the OPEX in the United Kingdom is underestimated. Adjusting the OPEX in either way will although not have significant impact on the results of the analysis.

\section{Discussions}

While low energy buildings bring significant energy savings compared to standard buildings the impact on the investment cost of the heat supply system is more subtle as discussed below.

\subsection{Impact on the building heat interface units}

When considering the difference of the standard and low energy buildings in respect to the heat supply unit it must be noted that the space heating demand is typically less than half of the total capacity demand, the other half is the DHW demand, which is unaffected by improvements of the building envelope, resulting in a relatively low capacity reduction of end-user equipment and minimal cost savings of the required heat pump. Further, the installation cost of the end-user equipment will not be particularly affected by a slightly smaller unit.

\subsection{Impact on the distribution network}

For the distribution network the saving potential due to more efficient buildings becomes increasingly relevant as more and more end-users are aggregated on the path to the heat source. The increasing saving potential is due to the possibility to take advantage of simultaneity of demand. For the distribution network the challenge is although that even with a $50 \%$ reduction in the capacity demand it may lead to only one pipe dimension smaller pipe, and that would mainly occur close to the heat source, which explains that there is only marginal difference in the cost of the distribution network for high and low energy buildings. 


\subsection{Impact on the central heat plant}

As mentioned above the biggest investment saving potential from energy efficiency improvements is achieved on an aggregated level, which is at maximum at the heat source of the district heating system. For the heat source it is important to note that for large systems the simultaneity of DHW demands is very low and the DHW peaks may even be handled by the thermal capacity of the distribution network. Simultaneity of the space heating is on the other hand not as aggressive, typically it can be discounted to $64 \%-75 \%$ of the sum of the individual capacity demand. The main part of the heat plant capacity is therefore due to space heating requirements, which enables significant cost savings for the central heat plant when going from high to low energy buildings. While this applies to both the ATDH and LTDH the benefit is significantly higher in the LTDH system, due to the relatively higher cost of central heat pump of the LTDH system compared to the heat exchanger station in the ATDH system.

\subsection{Sensitivity of the results}

In the case of Denmark, Figure 5, the results are robust and significant variation of any individual parameter would be needed to alter the results.

In case of the United Kingdom, Figure 6, the margins between the ATDH and LTDH systems are narrower. In the case of the United Kingdom the input energy is the most influential. But considering that the purpose of the two systems are identical it should be logical that any change in the tariff system should in principle affect both systems in similar manner. Of the remaining parameters the distribution grid is the most influential, it also has the highest level of uncertainty, in particularly in the ATDH system, due to a general lack of experience with ATDH systems. Nonetheless the margins between the ATDH and LTDH are more than $100 \%$ of the cost of the distribution network, indicating that the results are robust. To change the outcome there would need to be significant changes in at least two parameters.

\subsection{Comfort cooling}

When viewing literature about ATDH it is frequently mentioned that the heat pump used for heating could as well be used for comfort cooling during warm summer days. The cooling would than use the floor heating installation for cooling the building. This is an interesting advantage over traditional district heating systems that should be addressed in future improvements of this analysis. For fair comparison the cooling should be considered for both the ATDH and LTDH systems. In principle this would mean adding a heat pump module to the LTDH substation. The difference in the operation of the heat pump in the LTDH compared to the ATDH would be the heat sink temperatures, which would need to be higher for the LTDH case.

\section{Conclusions}

While it is not the purpose of the study to compare the results directly between the two countries it does show identical trends for both countries, which is that the centralized aspect of LTDH does give advantage for both countries.

Due to the higher share of fixed cost for the ATDH compared to the LTDH system the competitive advantage of LTDH increases with lower heating demands. This implies that for low energy buildings the next level competing technology for LTDH would be air source heat pumps and direct electric heating.

The economic comparison shows that LTDH is more cost efficient in both Denmark and the United Kingdom. The difference in Denmark is ranging from $43 \%$ to $50 \%$. In the United Kingdom the difference is much less, ranging from $12 \%$ to $22 \%$. There are three main influential parameters explaining the difference in the results between the two countries. The most influential one is the difference in electricity costs for industry and households. In Denmark the difference between industry and household power prices is significantly larger than in the United Kingdom. Secondly district heating is relatively immature technology in the United Kingdom, which both results in a premium price levels for establishing the distribution network and a slow uptake of advanced piping systems, that are generally applied in Denmark. The third parameter is the cost of the typical individual heat pumps applied in each country. The heat pump cost difference is explained by both the generally higher price levels in Denmark as well as a generally higher standard towards the heat pumps compared to the United Kingdom.

\section{Limitations of the study}

While the study applies standard practices, using simultaneity factors, to factor the impact of user behaviour on capacity requirement to the distribution network and the central heat sources, and a daily DHW profile, it does not address the impact of user behaviour on the hourly space heating demand. The space heating demand is based on the assumption that it is strictly dependent on the outdoor temperature. While the user behaviour is not expected to significantly alter the results it would be an interesting improvement area, especially for the ATDH system as it may provide insight into how the electricity tariff system would impact the variable cost of heating.

Due to the lack of data on the cost of installing ATDH distribution network, in both countries, there is an inherent uncertainty in the estimation of that parameter of the study. While it is not a dominating parameter it is a weak point that should be addressed.

\section{References}

[1] H. Lund, S. Werner, R. Wiltshire, S. Svendsen, J. E. Thorsen, F. Hvelplund and B. V. Mathiesen, "4th Generation District Heating (4GDH): Integrating smart thermal grids into 
future sustainable energy systems," Energy, vol. 68, pp. 1-11, 2014.

[2] S. Buffa, M. Cozzini, M. D’Antoni, M. Baratieri and R. Fedrizzi, "5th generation district heating and cooling systems: A review of existing cases in Europe" Renewable and Sustainable Energy Reviews, vol. 104, pp. 504-522, 2019.

[3] D. S. Østergaard, Heating of existing buildings by low-temperature district heating, Copenhagen: Technical University of Denmark, Department of Civil Engineering, 2018.

[4] M. Brand, Heating and Domestic Hot Water Systems in Buildings Supplied by LowTemperature District Heating, Copenhagen: Technical University of Denmark, Department of Civil Engineering, 2014.

[5] E. Zvingilaite, S. T. Ommen, B. Elmegaard and M. L. Franck, "Low Temperature District Heating Consumer Unit with Micro Heat Pump for Domestic Hot Water Preparation," in Proceedings of the 13th International Symposium on District Heating and Cooling, Copenhagen, 2012.

[6] P. A. Østergaard and N. A. Andersen, "Economic feasibility of booster heat pumps in heat pump-based district heating systems," Energy, vol. 155, pp. 921-929, 2018.

[7] S. T. Ommen, J. E. Thorsen, B. W. Markussen and B. Elmegaard, "Performance of ultra low temperature district heating systems with utility plant and booster heat pumps," Energy, vol. 137, pp. 544-555, 2017.

[8] R. Lund, D. S. Østergaard, X. Yang and B. V. Mathiesen, "Comparison of Low-temperature District Heating Concepts in aLong-Term Energy System Perspective," International Journal of Sustainable Energy Planning and Management, vol. 12, pp. 5-18, 2015.

[9] European Commission, "COMMUNICATION FROM THE COMMISSION TO THE EUROPEAN PARLIAMENT, THE COUNCIL, THE EUROPEAN ECONOMIC AND SOCIAL COMMITTEE AND THE COMMITTEE OF THE REGIONS, Powering a climate-neutral economy: An EU Strategy for Energy System Integration," 07 2020. [Online]. Available: https://ec.europa.eu/energy/sites/ener/files/ener gy_system_integration_strategy_.pdf.

[10] R. Schmidt, "IEA DHC Annex TS3: Hybrid Energy Networks," [Online]. Available: https://www.iea-dhc.org/theresearch/annexes/2017-2021-annex-ts3.html.

[11] C. H. Hansen, O. Gudmundsson and N. Detlefsen, "Cost efficiency of district heating for low energy buildings of the future," Energy, vol. 177 , pp. $77-86,2019$.
[12] A. Zhivov, Ed., Guide for Resilient Energy Systems Design in Cold and Arctic Climates, USA, 2021.

[13] O. Gudmundsson, J. E. Thorsen and A. Dyrelund, "District Energy - the resilient energy infrastructure," in Thermal Energy Systems Resilience in Cold/Arctic Climates Consultation Forum, Fairbanks, Alaska., 2020.

[14] M. Behnert and T. Bruckner, "Causes and effects of historical transmission grid collapses and implications for the German power system," Univeristy of Leipzig, Faculty of Economics and Management Science, Leipzig, 2018.

[15] Euroheat \& Power, "Guidelines for district heating substations," Euoheat \& Power, Brussels, 2008.

[16] Danish Energy Agency, "Technology Data Catalogue for Electricity and district heating production," Danish Energy Agency, Copenhagen, 2020

[17] Danish Energy Agency, "Technology Data for heating installations," Danish Energy Agency, Copenhagen, 2018.

[18] M. Wittenstein and G. Rothwell, "Project Costs of Generating Electricity.," International Energy Agency, Nuclear Energy Agency \& Organization for Economic Co-Operation and Development., 2015.

[19] Eurostat, "Statistics table NRG_PC_205: Electricity prices for non-household consumers," Eurostat, Brussels, 2021

[20] Eurostat, "Statistics table NRG_PC_203: Gas prices for household consumers," Eurostat, Brussels, 2021

[21] D. R. Gómez, J. D. Watterson, B. B. Americano, C. Ha, G. Marland, E. Matsika, L. N. Namayanga, B. Osman-Elasha, J. D. K. Saka and K. Treanton, "2006 IPCC Guidelines for National Greenhouse Gas Inventories. Chapter 2: Stationary Combustion," The Intergovernmental Panel on Climate Change, Hayama, Japan., 2006.

[22] Eurostat, "Statistics table NRG_PC 204: Electricity prices for household consumers," Eurostat, Brussels, 2021

[23] P. Lauenburg, P. O. Johansson and J. Wollerstrand, "District heating in case of power failure," Applied Energy, vol. 87, no. 4, pp. 1176-1186, 2010.

[22] A. Dyrelund and F.P. Bigum, "The four generations of district cooling", HotCool, vol. 3, 2020 . 